\title{
ОЦЕНКА ОСОБЕННОСТЕЙ РАЗВИТИЯ ДЕТЕЙ С ДИСФАЗИЕЙ (АЛАЛИЕЙ)
}

\author{
'Заваденко Н.Н.*, 'Щедеркина И.О., 'Заваденко А.Н., ${ }^{2}$ Козлова Е.В. \\ ${ }^{1}$ Кафедра неврологии, нейрохирургии и медищинской генетики педиатрического факультета Рос- \\ сийского наџионального исследовательского медицинского университета имени Н.И. Пирогова \\ Министерства здравоохранения Российской Федерации \\ ${ }^{2}$ Морозовская детская городская клиническая больница Департамента здравоохранения г. Москвы
}

Дисфазия развития (алалия) относится к тяжелым расстройствам речи у детей и рассматривается как ее системное недоразвитие в результате поражения корковых речевых зон в доречевом периоде. Проведено обследование 120 пациентов в возрасте от 3-х до 4,5 лет (89 мальчиков и 31 девочка) с дисфазией развития. С помощью методики DP-3 (Developmental Profile 3, Alpern G.D., 2009) у них обнаружено отставание от нормальных показателей не только в развитии речи, но и в формировании двигательных навыков, адаптивного поведения, социальноэмоциональной и познавательной сфер. Поэтому важное значение имеют ранние диагностика и коррекция нарушений развития речи у детей.

Ключевые слова: дисфазия развития, алалия, диагностика, лечение.

Речь для ребёнка - важнейшее средство связи с окружающим миром, взаимодействия с окружающими, получения информации для познавательной активности и развития мышления. Специфические расстройства развития речи (СРРP) по классификации МКБ-10 [1] (F 80.1 - расстройство экспрессивной речи и $\mathrm{F} 80.2$ - расстройство рецептивной речи) включают такие нарушения, при которых нормальное речевое развитие страдает на ранних этапах. При этом нарушения проявляются без предшествовавшего периода нормального развития речи. СРРР относятся к наиболее широко распространенным нарушениям развития, частота их встречаемости в детской популяции составляет 5-10\% [2, 3]. Алалия (по современным международным классификациям - "дисфазия" или "дисфазия развития") системное недоразвитие речи в результате поражения корковых речевых зон в доречевом периоде. Дисфазия развития является наиболее распространенным нарушением речевого развития на этапе, когда речь уже имеется, но при этом нарушена способность говорить, тогда как понимание речи может варьировать, но, по определению, развито значительно лучше [3, 4].

В современной международной литературе применяются оба термина (СРРР и "дисфазия развития"), при этом они относятся к одной и той же группе пациентов детского возраста. Но "дисфазия развития" считается более точной формулировкой диагноза, поскольку данный термин отражает как неврологический, так и эволюционно-возрастной аспекты данного расстройства $[4,5]$.

Недостаточный уровень развития речевых центров коры больших полушарий головного мозга, лежащий в основе дисфазии, может являться врожденным или приобретенным на ранних этапах онтогенеза, в доречевом периоде. Недоразвитие речи носит системный характер и характеризуется нарушением формирования не какого-либо одного, а практически всех компонентов речевой системы (звуковой стороны речи, фонематических процессов, лексики, грамматического строя) у детей с нормальным слухом и сохранным интеллектом. Наиболее часто встречающиеся варианты (экспрессивное и смешанное экспрессивно-рецептивное расстройства) проявляются значительным запаздыванием развития экспрессивной речи по сравнению с развитием понимания, при этом экспрессивная речь характеризуется значительными отклонениями. У детей затруднена организация речевых движений и их координация, тогда как понимание речи страдает менее значительно или не нарушено. Самостоятельная речь долго не развивается либо остается на уровне отдельных звуков и слов. Речь замедленна, обеднена, словарный запас ограничен обиходно-бытовой тематикой. В речи много оговорок (парафазий), перестановок, персевераций. Взрослея, дети понимают эти ошибки, пытаются их исправлять.

Перспективы психического развития, успешность обучения, школьная и социальная адаптация детей с дисфазией развития зависят от ее раннего выявления. Как реакция на речевую не-

*e-mail: zavadenko@mail.ru 
достаточность у многих детей с дисфазией развиваются невротические черты, замкнутость, негативизм, неуверенность в себе, внутренняя напряженность, повышенная раздражительность, обидчивость. При малой речевой активности страдает общая познавательная деятельность ребенка. Речь при дисфазии развития не служит полноценным средством коммуникации, организации поведения и индивидуального развития. Интеллектуальная недостаточность и ограниченный запас знаний, наблюдающиеся у пациентов в различные возрастные периоды, носят, таким образом, вторичный характер. Именно эта особенность отличает пациентов с дисфазией от детей с общей задержкой психического развития или легкой умственной отсталостью, для которых характерно равномерное неполное формирование всех высших психических функций и интеллектуальных способностей. С другой стороны, необходимо проводить разграничение между дисфазией и темповой задержкой развития речи, обусловленной дефицитом стимуляции речевого развития под влиянием неблагоприятных социальных факторов (недостаточного общения и воспитания).

При диагностике нарушений развития речи следует ориентироваться на показатели ее нормального формирования. В таблице 1 приводятся основные характеристики развития речи для детей в возрасте от 1 года до 6 лет.

Отсутствие помощи в раннем возрасте детям с недоразвития речи приводит к формированию целого ряда последствий. Это нарушения процесса общения и обусловленные ими трудности адаптации в детском коллективе и контактах с другими людьми, незрелость в эмоциональной сфере и поведении, недостаточная познавательная активность.

Целью исследования явилась оценка показателей возрастного развития детей с дисфазией по пяти сферам: двигательные навыки, адаптивное поведение, социально-эмоциональная сфера, познавательная сфера, речь и коммуникативные способности.

Материалы и методы. Обследованы 120 пациентов в возрасте от 3-х до 4,5 лет (89 мальчиков и 31 девочка) с дисфазией развития - расстройством развития экспрессивной речи (F
80.1 по МКБ-10 [1]) и картиной общего недоразвития речи (ОНР) 1-2 уровня по психологопедагогической классификации [6]. Дети направлялись к неврологу после логопедического обследования, динамическое наблюдение проводилось в амбулаторных условиях. Из изучаемой группы исключались дети, у которых отставание в развитии речи обусловливалось снижением слуха, умственной отсталостью, аутизмом, тяжелой соматической патологией, неполноценным питанием, а также влиянием неблагоприятных социальных факторов (недостаточным общением и воспитанием).

Исследование показателей возрастного развития осуществлялось с помощью методики Developmental Profile 3 (DP-3) [7]. Шкалы DP-3 предназначены для оценки особенностей развития ребенка по пяти сферам:

1. Двигательные навыки,

2. Адаптивное поведение,

3. Социально-эмоциональная сфера,

4. Познавательная сфера,

5. Речь и коммуникативные способности.

В настоящем исследовании применялась форма для структурированного опроса, проводимого специалистом с родителями.

Вопросы в беседе с родителями формулируются с целью выяснить, освоены ли ребенком соответствующие его возрасту навыки и способности к выполнению тех или иных действий/заданий. Таким образом, ответы на вопросы позволяют охарактеризовать уровень развития ребёнка в перечисленных пяти основных сферах.

Каждая из шкал разделена на возрастные периоды: от 1-го мес. до 1 года 11 мес., от 2 лет 0 мес. до 3 лет 11 мес., от 4 лет 0 мес. до 5 лет 11 мес. На основании полученных данных определяется, какому возрасту соответствует уровень развития ребенка в каждой из сфер и на какой возрастной интервал у него имеется отставание от нормальных показателей для его календарного возраста.

Результаты и их обсуждение. При исследовании анамнеза многие родители указывали, что уже в раннем возрасте обращали внимание на отсутствие или ограничение лепета у детей. Родители отмечали молчаливость, подчеркивали, что ребенок все понимает, но не 


\section{Показатели развития речи у детей от 1 года до 6 лет}

\begin{tabular}{|c|c|}
\hline Возраст & Речевые навыки \\
\hline \multicolumn{2}{|l|}{ 2-й год } \\
\hline 1 год & появление однословных предложений \\
\hline 1 год 3 месяца & запас слов до 30 \\
\hline 1 год 6 месяцев & запас слов до 40-50, легко повторяет часто слышимые слова \\
\hline 1.5-2 года & появление фраз, двухсловных предложений \\
\hline $1.5-2$ года & первый период вопросов: «Что это?», «Куда?», «Где?» \\
\hline 2 года & запас слов до 200-300 \\
\hline \multicolumn{2}{|l|}{ 3-й год } \\
\hline 2 года & $\begin{array}{llll}\begin{array}{l}\text { начинает пользоваться } \\
\text { предлогами }\end{array} & \text { прилагательными, } & \text { местоимениями } & \text { и } \\
\end{array}$ \\
\hline 2 года & появление трехсловных предложений \\
\hline 2 года 6 месяцев & появление многословных предложений \\
\hline $\begin{array}{l}2 \text { года } 6 \text { месяцев } \\
-3 \text { года }\end{array}$ & $\begin{array}{l}\text { могут сохраняться трудности звукопроизношения } \\
\text { шипящие, сонорные звуки) }\end{array}$ \\
\hline 3 года & запас слов до 800-1000 \\
\hline \multicolumn{2}{|l|}{ 4-й год } \\
\hline 3 года & $\begin{array}{l}\text { употребление грамматических форм: изменения существительных по } \\
\text { падежам и числам, глаголов - по родам, временам, числам и лицам }\end{array}$ \\
\hline 3-4 года & второй период вопросов: «Почему?», «Когда?» \\
\hline 3-4 года & фразы становятся длиннее, их смысл усложняется \\
\hline 3-4 года & $\begin{array}{l}\text { могут сохраняться недостатки в произношении ряда слов (длинных и } \\
\text { малознакомых), нечеткость произношения ряда звуков }\end{array}$ \\
\hline 4 года & $\begin{array}{l}\text { дети изъясняются развернутыми предложениями, включающими } \\
\text { почти все части речи }\end{array}$ \\
\hline 4 года & $\begin{array}{l}\text { умеют группировать предметы по классам: одежда, посуда, мебель, } \\
\text { животные и др. }\end{array}$ \\
\hline 4 года & запас слов до 2000 \\
\hline \multicolumn{2}{|l|}{ до 6 лет } \\
\hline 4-5 лет & высказывания приобретают форму короткого рассказа \\
\hline 4-5 лет & исчезают почти все возрастные неправильности произношения \\
\hline 5 лет & $\begin{array}{l}\text { умеют составить по картинке рассказ из нескольких предложений, } \\
\text { правильно отвечают на вопросы по сюжету рассказа }\end{array}$ \\
\hline 5 лет & запас слов до 2500 \\
\hline 6 лет & $\begin{array}{l}\text { в речи возрастает количество простых распространенных и сложных } \\
\text { предложений, во фразах используются все основные части речи }\end{array}$ \\
\hline 6 лет & отсутствуют недостатки произношения звуков и слов \\
\hline 6 лет & $\begin{array}{l}\text { умеют составить рассказ (пересказ) из 40-50 предложений с развитием } \\
\text { сюжета, отразив в нем события прошлого, настоящего или будущего }\end{array}$ \\
\hline
\end{tabular}

желает говорить. Вместо речи развивались мимика и жестикуляции, которыми дети пользовались избирательно в эмоционально окрашенных ситуациях. Первые слова и фразы появлялись поздно. Родители при этом отме- чали, что кроме отставания в речи, в целом дети развиваются нормально. Дети имели скудный активный словарь, пользовались лепетными словами, звукоподражаниями и звуковыми комплексами. В речи отмечалось много 
оговорок, на которые дети обращали внимание и пытались исправлять ошибочно сказанное. На момент обследования объем активного словаря (запас произносимых слов) у детей с ОНР 1-го уровня не превышал 15-20 слов, а ОНР 2-го уровня насчитывал от 20 до 50 слов.

В таблице 2 представлены результаты обс- ледования, показывающие, на какой возрастной интервал имелось отставание от нормальных показателей в трех группах детей с дисфазией развития, разделенных по возрасту: (1) от 3 лет 0 мес. до 3 лет 5 мес.; (2) от 3 лет 6 мес. до 3 лет 11 мес.; (3) от 4 лет 0 мес. до 4 лет 5 мес..

Таблица 2.

Отставание показателей развития (в месяцах, М m) в трех возрастных группах детей с дисфазией

\begin{tabular}{|c|c|c|c|c|c|}
\hline $\begin{array}{c}\text { Группы } \\
\text { пациентов }\end{array}$ & $\begin{array}{c}\text { Двигатель- } \\
\text { ные навыки }\end{array}$ & $\begin{array}{l}\text { Адаптив- } \\
\text { ное } \\
\text { поведение }\end{array}$ & $\begin{array}{c}\text { Социально- } \\
\text { эмоциональ- } \\
\text { ная сфера }\end{array}$ & $\begin{array}{l}\text { Познава- } \\
\text { тельная } \\
\text { сфера }\end{array}$ & $\begin{array}{c}\text { Речь и } \\
\text { коммуни- } \\
\text { кация }\end{array}$ \\
\hline $\begin{array}{l}\text { Дети с дисфазией } \\
\text { от } 3 \text { лет } 0 \text { мес. до } 3 \\
\text { лет } 5 \text { мес., } \\
\text { n=73 }\end{array}$ & $6,7 \pm 0,3$ & $3,3 \pm 0,3$ & $4,9 \pm 0,3$ & $6,9 \pm 0,3$ & $17,3 \pm 0,4$ \\
\hline $\begin{array}{l}\text { Дети с дисфазией } \\
\text { от } 3 \text { лет } 6 \text { мес. до } 3 \\
\text { лет } 11 \text { мес., } \\
\text { n=25 }\end{array}$ & $12,2 \pm 0,5^{*}$ & $8,2 \pm 0,4^{*}$ & $10,4 \pm 0,6^{*}$ & $11,8 \pm 0,5^{*}$ & $21,2 \pm 0,8^{*}$ \\
\hline $\begin{array}{l}\text { Дети с дисфазией } \\
\text { от } 4 \text { лет } 0 \text { мес. до } 4 \\
\text { лет } 5 \text { мес., } \\
\text { n=22 }\end{array}$ & $17,2 \pm 0,4^{*}$ & $13,6 \pm 0,5^{*}$ & $14,9 \pm 0,5^{*}$ & $18,0 \pm 0,4^{*}$ & $27,3 \pm 0,5^{*}$ \\
\hline
\end{tabular}

Достоверность различий с предыдущей возрастной группой: *p<0,001.

Закономерным представляется то, что наиболее значительным было отставание в формировании речи и коммуникативных способностей, но, кроме того, степень данного отставания увеличивалась - от $17,3 \pm 0,4$ мес. в 1 -й

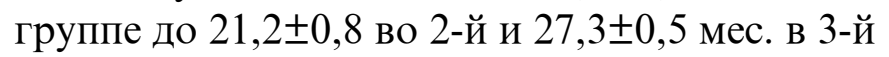
группе. Наряду с увеличением выраженности отличий от здоровых сверстников в речевом развитии, отставание во всех остальных сферах не только сохранялось, но и становилось более значительным с каждым полугодовым возрастным периодом (табл. 2). Это свидетельствует, с одной стороны, о значительном влиянии речи на другие сферы развития ребенка, а с другой - о тесной взаимосвязи и неразрывности различных аспектов индивидуального развития.

При сопоставлении уровня формирования двигательных навыков, адаптивного поведения, социально-эмоциональной сферы, поз- навательной сферы, речи и коммуникативных способностей у мальчиков и девочек с дисфазией развития (для этого была выбрана самая большая подгруппа пациентов в возрасте 3 лет 0 мес. до 3 лет 5 мес.) достоверных различий обнаружено не было (табл. 3). Таким образом, отставание от ровесников в изученных сферах существенно не зависело от пола и примерно в одинаковой степени проявлялось как у мальчиков, так и девочек с дисфазией развития.

С другой стороны, отставание от сверстников в исследованных сферах характеризовалось определенной зависимостью от тяжести задержки речевого развития. Наиболее четко данная взаимосвязь прослеживалась в возрастной группе от 3 лет 0 мес. до 3 лет 5 мес. (табл. 4), в которой у пациентов с ОНР 1-го уровня имелось достоверно более значительное отставание в формировании двигатель- 


\section{Таблица 3.}

Отставание показателей развития (в месяцах, $\mathrm{M}$ m) у мальчиков и девочек с дисфазией в возрасте 3 лет 0 мес. до 3 лет 5 мес.

\begin{tabular}{|l|c|c|c|c|c|}
\hline \multicolumn{1}{|c|}{$\begin{array}{c}\text { Группы } \\
\text { пациентов }\end{array}$} & $\begin{array}{c}\text { Двигатель- } \\
\text { ные } \\
\text { навыки }\end{array}$ & $\begin{array}{c}\text { Адаптив- } \\
\text { ное } \\
\text { поведение }\end{array}$ & $\begin{array}{c}\text { Социально- } \\
\text { эмциональ- } \\
\text { ная сфера }\end{array}$ & $\begin{array}{c}\text { Познава- } \\
\text { тельная } \\
\text { сфера }\end{array}$ & $\begin{array}{c}\text { Речь и } \\
\text { коммуни- } \\
\text { кация }\end{array}$ \\
\hline $\begin{array}{l}\text { Мальчики с } \\
\text { дисфазией, } \\
\text { n=49 }\end{array}$ & $6,4 \pm 0,4$ & $3,3 \pm 0,3$ & $5,1 \pm 0,4$ & $7,1 \pm 0,4$ & $17,5 \pm 0,5$ \\
\hline $\begin{array}{l}\text { Девочки с } \\
\text { дисфазией, } \\
\text { n=24 }\end{array}$ & $7,3 \pm 0,5$ & $3,2 \pm 0,4$ & $4,6 \pm 0,6$ & $6,4 \pm 0,6$ & $16,9 \pm 0,6$ \\
\hline
\end{tabular}

ных навыков наряду с тенденцией к большему отставанию в остальных сферах, нежели у детей с ОНР 2-го уровня. В возрасте от 3 лет 6 мес. до 3 лет 11 мес. и от 4 лет 0 мес. до 4 лет 5 мес. подобные различия нивелировались при одновременном значительном нарастании в группах детей с ОНР 1-го и 2-го уровней интервалов, на которые запаздывало формирование двигательных навыков, адаптивного поведения, социально-эмоциональной и познавательной сфер. Это еще раз подтверждает, что у детей с дисфазией как при OHР 1-го, так и 2-го уровней, выраженность отставания в формировании перечисленных навыков и сфер может заметно усугубляться с возрастом.

Таблица 4.

\section{Отставание показателей развития (в месяцах, М m) у пациентов с ОНР 1-го уровня} и ОНР 2-го уровня в трех возрастных группах

\begin{tabular}{|c|c|c|c|c|c|}
\hline $\begin{array}{c}\text { Группы } \\
\text { пациентов }\end{array}$ & $\begin{array}{l}\text { Двигатель- } \\
\text { ные навыки }\end{array}$ & $\begin{array}{c}\text { Адаптив- } \\
\text { ное } \\
\text { поведение }\end{array}$ & $\begin{array}{c}\text { Социально- } \\
\text { эмоциональ- } \\
\text { ная сфера }\end{array}$ & $\begin{array}{c}\text { Познава- } \\
\text { тельная } \\
\text { сфера }\end{array}$ & $\begin{array}{c}\text { Речь и } \\
\text { коммуни- } \\
\text { кация }\end{array}$ \\
\hline $\begin{array}{l}\text { Дети с дисфазией } \\
\text { от } 3 \text { лет } 0 \text { мес. до } 3 \\
\text { лет } 5 \text { мес.: } \\
\text { ОНР } 1 \text { ур., n=42 } \\
\text { OНР } 2 \text { ур., n=31 }\end{array}$ & $\begin{array}{c}7,3 \pm 0,4^{*} \\
5,9 \pm 0,4\end{array}$ & $\begin{array}{l}3,5 \pm 0,4 \\
2,8 \pm 0,3\end{array}$ & $\begin{array}{l}5,1 \pm 0,5 \\
4,6 \pm 0,5\end{array}$ & $\begin{array}{l}7,1 \pm 0,4 \\
6,5 \pm 0,5\end{array}$ & $\begin{array}{c}18,3 \pm 0,5^{* *} \\
15,9 \pm 0,5\end{array}$ \\
\hline $\begin{array}{l}\text { Дети с дисфазией } \\
\text { от } 3 \text { лет } 6 \text { мес. до } 3 \\
\text { лет } 11 \text { мес.: } \\
\text { ОНР } 1 \text { ур., n=11 } \\
\text { ОНР } 2 \text { ур., n=14 }\end{array}$ & $\begin{array}{l}12,5 \pm 0,9 \\
12,2 \pm 0,6\end{array}$ & $\begin{array}{l}8,0 \pm 0,6 \\
8,5 \pm 0,7\end{array}$ & $\begin{array}{c}9,8 \pm 0,8 \\
10,8 \pm 0,9\end{array}$ & $\begin{array}{l}11,9 \pm 0,7 \\
11,8 \pm 0,7\end{array}$ & $\begin{array}{l}21,4 \pm 1,4 \\
21,0 \pm 0,9\end{array}$ \\
\hline $\begin{array}{l}\text { Дети с дисфазией } \\
\text { от } 4 \text { лет } 0 \text { мес. до } 4 \\
\text { лет } 5 \text { мес.: } \\
\text { ОНР } 1 \text { ур., n=8 } \\
\text { ОНР } 2 \text { ур., n=14 }\end{array}$ & $\begin{array}{l}16,5 \pm 0,7 \\
17,4 \pm 0,3\end{array}$ & $\begin{array}{l}12,9 \pm 1,0 \\
13,6 \pm 0,5\end{array}$ & $\begin{array}{l}13,8 \pm 0,6 \\
15,8 \pm 0,6\end{array}$ & $\begin{array}{l}17,6 \pm 0,8 \\
18,1 \pm 0,5\end{array}$ & $\begin{array}{l}28,1 \pm 1,0 \\
26,9 \pm 0,6\end{array}$ \\
\hline
\end{tabular}

Достоверность различий между подгруппами пациентов с ОНР 1-го уровня и ОНР 2-го уровня: *p<0,05, **p<0,01. 
Заключение. В настоящем исследовании подтверждено, что у детей с дисфазией нарушения в речевом развитии проявлялись не изолированно, а также затрагивали другие важные аспекты индивидуального развития. При проведении обследования с помощью методики DP-3 [7] трех групп пациентов с дисфазией от 3х до 4,5 лет, разделенные по возрасту на полугодовые интервалы, нами обнаружено отставание от нормальных показателей в формировании всех изучавшихся сфер, в том числе двигательных навыков, адаптивного поведения, социально-эмоциональной сферы, познавательной сферы. При этом степень данного отставания возрастала у детей 4-4,5 лет по сравнению с теми, которые были младше на один год, с $6,7 \pm 0,3$ до 17,2 $\pm 0,4$ мес. в двигательной сфере, с $3,3 \pm 0,3$ до $13,6 \pm 0,5$ мес. в адаптивном поведе-

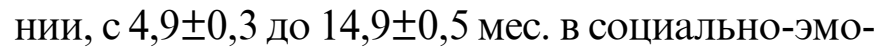
циональной сфере и с $6,9 \pm 0,3$ до $18,0 \pm 0,4$ мес. в познавательном развитии $(\mathrm{p}<0,001)$. Это происходило на фоне увеличения отставания в развитии речи и коммуникативных способностей с 17,3 $\pm 0,4$ до 27,3 $\pm 0,5$ мес., что подтверждает ключевое значение функций речи и тесную взаимосвязь в формировании всех компонентов индивидуального развития. Одновременно результаты обследования детей с дисфазией с помощью методики DP-3 показывают, что их нервно-психическое развитие носит дисгармоничный характер.

Поэтому важное значение приобретают

\section{ЛИТЕРАТУРА}

1. МКБ-10 - Международная классификация болезней (10-й пересмотр). Классификация психических и поведенческих расстройств. Исследовательские диагностические критерии. - СПб., 1994.

2. Айкарди Ж., Бакс М., Гиллберг К. Заболевания нервной системы у детей. Пер. с англ. под ред. А.А. Скоромца. Москва, Издательство Панфилова, БИНОМ, 2013, $1036 \mathrm{c}$.

3. Корнев А.Н. Основы логопатологии детского возраста: клинические и психологические аспекты. - СПб.: Речь, 2006. - 380 с.

4. Ньокиктьен Ч. Детская поведенческая неврология, ранние диагностика и коррекция нарушений развития речи у детей. Основными направлениями коррекции при нарушениях развития речи у детей являются: логопедическая, психолого-педагогическая, психотерапевтическая помощь ребенку и его семье, а также медикаментозное лечение. Поскольку дисфазия представляют собой сложную медико-психолого-педагогическую проблему, особое значение при организации помощи таким детям приобретают комплексность воздействия и преемственность работы с детьми специалистов различного профиля (врачей, логопедов, психологов, педагогов). Планирование и проведение коррекционных мероприятий, в том числе медикаментозной терапии, должно осуществляться по индивидуальным планам для каждого ребенка. Своевременное применение препаратов ноотропного ряда в лечении дисфазии у детей способствует наиболее полной коррекции имеющихся нарушений. В недавно проведенном исследовании [8] показано, что препараты ноотропного ряда (пантогам, церебролизин, энцефабол) оказывают у детей с дисфазией развития положительное влияние на показатели экспрессивной и импрессивной речи, а также речевое внимание, способствуют уменьшению эмоциональных и психосоматических нарушений, церебрастенических проявлений, моторной неловкости, улучшению характеристик активного внимания, поведения и эмоционального контроля.

том 2. - М.: Теревинф, 2010. - 336 с.

5. Beesems M.A.G. Developmental Dysphasia. Theory Diagnosis and Treatment. Amsterdam: Developmental Dysphasia Foundation, 2007, 11 p.

6. Левина Р.Е. Основы теории и практики логопедии. М.: Просвещение, 1968. - 367 с.

7. Alpern G.D. Developmental Profile 3, DP-3 Manual. Western Psychological Services, Los Angeles, 2009, 195 p. 8. Заваденко Н.Н., Козлова Е.В. Лекарственная терапия дисфазии развития у детей ноотропными препаратами. Вопросы практической педиатрии, 2013, т. 8, №5, c. 24-28 


\title{
SUMMARY
}

\section{ASSESSMENT OF THE DEVELOPMENTAL FEATURES IN CHILDREN WITH DYSPHASIA (ALALIA)}

\author{
${ }^{1}$ Zavadenko N.N., ${ }^{2}$ Shchederkina I.O., ${ }^{2}$ Zavadenko A.N., ${ }^{2}$ Kozlova E.V. \\ ${ }^{I}$ N.I.Pirogov Russian National Research Medical University, Neurology, Neurosurgery and Medical \\ Genetics Department of Pediatric Faculty, Moscow, Russian Federation; \\ ${ }^{2}$ Morozov Pediatric City Clinical Hospital, Moscow, Russian Federation
}

The developmental dysphasia (alalia) represents a severe speech and language disorder in children due to the brain cortex language areas underdevelopment or damage in the preverbal period. 120 patients with developmental dysphasia were studied aged from 3 to 4,5 years ( 89 males and 31 females). The assessment with DP3 tool (Developmental Profile 3, Alpern G.D., 2009) revealed the developmental delay not only in communication skills, but also in physical/motor, adaptive behavior, social-emotional and cognitive areas. Thus, early diagnosis and treatment of the disorders in speech and language development are very important.

Keywords: developmental dysphasia, alalia, diagnosis, treatment.

\section{XÜLASə}

\section{DISFAZIYALI (ALALIYALI) UŞAQLARIN INKIŞAF XÜSUSIYYYӨTLӘRININ QIYMMTLONDIRILMOSI}

\author{
${ }^{1}$ Zavadenko N.N., ${ }^{1}$ Şederkina İ.O., ${ }^{2}$ Zavadenko A.N., ${ }^{2}$ Kozlova E.V. \\ ${ }^{1}$ N.I. Piraqov adına Rusiya Milli Tadqiqat Tibb Universitetinin pediatrik fakultosinin nevrologiya, ney- \\ rocarrahiyy vo tibbi genetika kafedrasi, Moskva, $R F$; \\ ${ }^{2}$ Morozov uşaq şəhər kliniki xəstวxanast, patoloji anatomiya şöbəsi, Moskva, RF
}

İnkişaf disfaziya (alaliya) uşaqlarda nitqin ağır pozulmalarına aid edilir və nitqə qədərki dövrdə qabığın nitq zonalarının zədələnməsi nəticəsində nitqin sistemli inkişafdan qalması kimi qiymətləndirilir. İnkişaf disfaziyası olan 3-4,5 yaş arası 120 pasiyent (89 oğlan və 31 qiz) tədqiqata cəlb edilmişdir. DP-3 metodu (Developmental Profile 3, Alpern G.D., 2009) ilə bu xəstələrdə əsas göstəricilərdən geriləmə təkcə nitqin inkişafında deyil, həm də hərəki vərdişlərin formalaşmasında, adaptiv davranışda, sosial-emosional və qavrama sferasında da qyedə alınmışdır. Ona görə də erkən diaqnostika və nitqin inkişaf pozulmasının korreksiyası uşaqlarda vacib əhəmiyyətə malidir.

Açar sözlər: inkişaf disfaziyası, alaliya, diaqnostika, müalicə.

Redaksiyaya daxil olub: 02.06.2015

Çapa tövsiyz olunub: 29.06.2015

Rayçi: t.e.d. Hasənov R.L. 